\title{
Framing Situated Professional Knowledge in Online Learning Communities
}

\author{
Susan Gasson \\ Drexel University \\ sgasson@drexel.edu
}

\author{
James Waters \\ Neumann University \\ watersj@neumann.edu
}

\begin{abstract}
This paper deepens the theoretical understanding that underpins collaboration through social interaction in professional online learning environments. It explores the use of framing as a theoretical lens to assess "situated" learning in online graduate education. We explore how collaborative knowledge construction is framed in an intense 10 week graduate IS Project Management course. We present a taxonomy of frame challenging, problematization, and legitimation to demonstrate how individual and collective forms of knowledge construction contribute to group learning about professional practice in the context of action. We close with a model that demonstrates how community knowledge is coconstructed through sequences of contextualized frame-proposal, reflective comparison with own experience, frame-problematization and debate, and generic-legitimation of a consensus frame.
\end{abstract}

\section{Introduction}

The ongoing and notable growth in online learning brings with it some definite problems. There are for instance several challenges involved in attempting to emulate or relocate the kind of situated learning that is present in professional settings into the online environment. The community of practice that a professional will work within is different from an online community of learners. It is not simply the lack of face to face communication. Many professionals work in globally distributed teams and may never physically meet their colleagues. There are many rich technology mediated methods of communication. But this is different than the enculturation and sensitization to the contingencies of context that are required for expertise in situated practice in the IT/IS professions. The positivistic and individual-oriented learning evaluation required in University course environments have different goals, outcomes, and levels of analysis [13]. While of clear value in evaluating students' roles in productive argumentation and reasoning practices, employing an individual level of analysis to understand how students learn in online, professional courses ignores the sociocultural context of work, so fails to account for the experiential and interactive learning that underpins individual decisions and knowledge construction in real-world, professional practice.

In this paper, we suggest a complementary approach that explores the construction of socially negotiated meaning and identity through the use of frames that allow us to understand the world [6]. We start with a brief exposition of framing and develop a taxonomy of framing activities based on an analysis of a 10 week, graduate (MS) IS Project Management course. We suggest ways of scaffolding professional courses to incentivize peer knowledge exchange that situates community learning in the context of practice. We present examples and findings from our analysis to indicate how a professional course instructor might evaluate what learning is taking place in order to incentivize contextual knowledge sharing between peer learners. We end with a model of community learning from social framing activities as tool for the evaluation of collaborative knowledge building for online graduate education.

\section{Conceptual underpinnings}

\subsection{Deep learning}

Instructors frequently talk of a achieving the goal of "deep learning" without understanding what this means. The concept derives from a study by Marton and Säljö [9], where students were asked to study an academic paper for a test. Some students simply memorized random information snippets, while others searched for a structure of interpretation within the text to which they could relate its underlying concerns, its implications, and its significance to the course. Subsequent studies noted that students who employed this "deep learning" approach understood more of the subject matter, were able to abstract and apply its 
principles to other contexts, and were able to identify key elements of course knowledge more effectively than those employing the superficial approach [12]. Deep learning therefore provides a mechanism by which students become sensitized to context-specific structures of interpretation, or "patterns" that indicate what elements to look for and how to act in novel situations [13].

\subsection{Making sense of the world through framing}

We call these structures of interpretation frames [of reference] [14]. Over many years we build a repertoire of frames, based on personal experience and on frames that others suggest to us in discourse [6]. Frames also derive from the implicit perspectives (skills) that we acquire through participating in joint practice with others, for example as a member of a specific community of practice [8]. In the MIS literature, these joint frames are referred to as "technological frames" after Bijker's studies of how technology is socially constructed [2]. We prefer the term frame as it has a wider and more technologyneutral meaning. Individuals with a similar experiential background, when confronted with similar situations will build frames that have large degrees of commonality. This is why we relate frames to situated knowledge: knowledge that is located in a specific situation or context of practice. The language used, the stories told and the belief-structures that are embedded into professional settings indicate a shared interpretation scheme, where members of a community of practice make sense of the world in very similar ways [8].

Sensemaking is integral to constructing a shared culture and sense of identity, that is communicated through language and practices that define "how we do things here" [16]. This allows people who collaborate in work or study to build a shared set of practices, culture, values, and norms that represent "professional practice” [8]. The existence of a shared set of meanings allows members of a community to work together without constantly needing to confer about what they should do next - or how they should do it - which reinforces the sense of community [16].

\subsection{Learning through breakdowns}

Framing provides a common set of interpretations that allow us to make sense of a situation based on our experience of similar situations and our membership of professional groups [8]. But uncritical repetition of learned behavior leads us to act in automatic mode, where we don't stop to consider if we are doing things in the best way [6]. When we discuss or reflect upon the processes of professional practice, we may be confronted by inconsistencies between what we assume or believe and what specific use or development process will achieve our goal. As a result, we may suffer a cognitive breakdown that causes us to reexamine the assumptions and beliefs that led to the initial frame. A breakdown is "a situation of nonobviousness" that makes us break out of our existing frame to reflect on the consequences of our actions [17, p. 165]. By exposing relevant aspects of how the current problem-situation is structured in our heads, we can surface our implicit assumptions and challenge the prevailing frame. Breakdowns allow us to make sense of when, why, and under what conditions various work practices succeed or fail [11]. For example, when we are confronted with a situation where software requirements have not been defined in advance of system development, we might realize that we cannot proceed with traditional systems development methods. We must either adapt our intended development method to surface requirements as we work, or adapt our planned process to gather requirements before we start development.

\subsection{Community knowing and learning}

We need to consider two levels of knowing in an online community of inquiry. One level captures the interactive framing and knowledge co-construction that occurs as individual participants build on the suggestions of others. The second form of community framing considers what the community knows or decides as a community.

The first form of community knowing takes place through interactions. The resulting knowledge is distributed as it is "stretched across" rather than shared between participants in the debate that produced it. Some participants will understand more than others about what was concluded between them, depending on their prior experience, which provides an interpretive filter for the knowledge they are presented with. Although the social and context-related framing that debate participants experienced during interactions may be lost to those who did not participate in the original discussion, an online learning environment can capture textual statements that show others' structures of interpretation. This is of value not just for researchers but also for the community of learners, who can use this as a form of transactive memory, leading to vicarious learning [15]. Both constituencies may observe the evolution of shared knowledge through both the content and process of discussions. New or extended frames of reference may be presented to the community but without substantial evidence or justification are unlikely to gain traction. Whenever an 
online learner makes any kind of contribution to the community discussion they are (possibly unwittingly) exposing something about their frame of reference or their opinion of a community frame, even if it is only "I agree with Fred".

The second form of knowing is represented by a community frame that reflects how participants 'perform' professional work-roles using language and forms of expression that allow them to construct a shared identity through interaction [8]. The collective acceptance and reproduction of "what the community knows" provide a set of discursive acts that legitimize frames during debate, objectifying and "institutionalizing" community knowledge [1]. Students will reproduce prior debates in statements like, "a previous thread concluded that people skills are the most important quality for a project manager.” This becomes accepted by others and forms a sort of community "truth."

A dominant community frame may obstruct innovation and learning, as it reinforces consensus and joint identity (and so is hard to break). But even consensus frames can be broken by sufficient evidence for its limitations or by the value found in a conflicting frame [6]. This occurs when social debate challenges our co-constructed perception of professional practice or when we essay that form of practice and it fails to achieve the desired outcome. After Foucault, we employ the concept of problematization, a technique where objects or situations are de-familiarized in order to provide an "object for thought" that exposes the internal structures and inconsistencies in participants' belief-systems [3]. Problematization is achieved by employing an analogy, metaphor, or deconstruction that highlights the inadequacy of the existing frame.

\subsection{Community learning as group memory}

The persistent nature of online debate means that community members can go back to reference prior frames that were co-constructed through interactive discussion - this provides a form of group memory that verbal discussions lack. Online community members are aware of the perspectives of other users who interact with them, making their public statements for an 'audience' of non-interacting readers (lurkers or passive learners), critics (those with competing perspectives), supporters (those who have demonstrated similar frames), and moderators such as the instructor [10]. Frame persistence may cause students to become aware when their individual framing of a situation conflicts with previouslydiscussed ways of framing similar situations, causing a form of communal metacognition where they adapt and modify their perspectives to integrate prior “community frames." This mechanism forms and reinforces a shared sense of identity, in terms of "how we think of practice here" [8]. Online discussions demonstrate a wide range of quality of contribution from participants [4]. One might assume that the kinds of framing behavior would illustrate similar levels of commitment to community knowledge building ranging from none at all to wholehearted engagement and iconoclastic behavior [15]. The frame content is conveyed through the language terms, metaphors, analogies, and stories recounted in discussion posts. This can be used to identify structural dimensions or elements relevant to the context of action that individuals employ to interpret a problem situation. As the focus of this study is collaborative sensemaking in a situated learning that is simulated by discussion of real-world problem-situations, we defined the content of a frame as representing structures of interpretation [16]. We used grounded theory analysis to explore the processes by which the structures of interpretation required for deep learning were individually and jointly constructed to produce community knowledge.

\section{Research Method}

This paper presents findings from the analysis of a 10 week graduate Information Systems Project Management course at a North American University. The examples explore how discursive interactions (role-behaviors) and the framing and co-construction of situated knowledge come together to provide a multi-level framework for community learning that provides indicators of how we may simulate experiential learning in professional online courses. Data were gathered from the asynchronous, online discussion boards that formed a key component of online graduate Information Systems and Information Science courses at a North American University. Our goal was to develop a theory of knowledge construction via framing, an approach that has not been applied to online learning previously. We therefore used a grounded theory approach to data collection and analysis [5]. Our core category was defined as the framing process, defined as imposing some structure of interpretation on a problem-situation (the object of student discussions). We employed co-coder resolution of meaning rather than co-coder comparison, as it is more constructive to identify where there are differences of interpretation and discuss these until both researchers understand them in depth, than to predefine a concrete coding scheme that prevents category emergence. Following van Gorp [7], we produced a matrix of two dimensions of open coding to compare interaction effects between students' framing perspectives (structural frameworks for the problem- 
situation identified in discussion content) and students' reasoning devices (knowledge-construction behaviors).

The grounded theory analysis was supplemented with visualization tools (graphs, distributions, social network models, and sequence maps) to uncover patterns in the emerging categories of framing. These were recorded in memos, which formed the basis of another round of constant comparative coding. The substantive theory presented here results from a single course (although we did adopt a constant comparative approach between discussion threads and weeks of discussion). It suggests a tentative theory of framing in communities of inquiry that may assist in preparing for, and managing, interactive situated knowledge construction in online professional courses.

Students do not expect to engage in peer-learning in online courses, so will revert to didactic forms of question-response directed to the instructor unless they are directed to behave otherwise. We provided students with a grading rubric that rewarded interactive debate and which incentivized knowledge-building by asking students to "complicate the debate by developing ideas from other students”. Early, formative feedback was provided to manage expectations, critiquing the extent to which a post advanced new ideas or developed the ideas of others. Students were encouraged to communicate the contextual aspects of professional practice (e.g. "I'd like to see concrete examples of when and how this is important”).

\section{Framing knowledge in debate}

\subsection{Problem-framing and knowledge-building}

Early analysis suggested that students actively built on - and developed - the frames suggested by others. This was encouraging, as it meant incentives to stimulate communal knowledge building were working! Table 1 shows an extract from a discussion thread considering the question "What skills are most important to Software Project Management?” Student S10 frames a response to the question by arguing that, while an ability to understand the project scope, and experience with the project management methods in use are both important, interpersonal skills, problem definition and group leadership are more important. This statement followed from a few early posts, where students had suggested that the ability to communicate, organize project resources, and translate the requirements so that all stakeholders understood what was being proposed were key PM skills. S10 is building on these early statements in this post, to relate what are abstract posts by others to a specific example. They explain the example, and then synthesize their framework with key elements that others had proposed.
The power of a story in mobilizing frame adoption is illustrated by the way that subsequent participants in the thread do not adopt the formal (synthesized) frame that S10 ended with, but the initial frame that the story illustrated. S7 comments on the narrative, then adds a dimension to the framework that is suggested by their own experience, problematizing the frame by presenting two alternate constructions for the failure in S10's story. S10 rejects S7's problematization, explaining that the failure resulted from a lack of understanding of the system "problem" which caused the PM to focus on low-level task management aspects of the project. S23 picks up the dichotomy, problematizing the frame by suggesting that complex problems need a framework where the known requirements are managed with simple project methods and the unknown requirements are investigated using a separate method. They note that this requires a more knowledgeable and experienced manager than in S10's story - although they do not explain this well. Finally, S9 enters the fray, to synthesize the discussion, explaining the issues that S23 failed to make clear and assembling the learning points suggested by various participants into a framework that relates practice to the context of a typical IS development project.

\subsection{Problem-framing and knowledge-building}

Exploring the role of various framing behaviors in community knowledge construction, we were able to define a set of categories that combined the two dimensions. Our categories of framing behavior are defined in Table 2, focusing on their role in framing community knowledge, as distinct from the turn-taking and interactive argumentation behaviors that are typically analyzed in online discourse. This allowed us to model the processes by which community knowledge - knowledge that served as a learning resource for course members - was co-constructed, tested, problematized and modified, and generalized to become a legitimate community perspective.

\section{Analyzing Community Learning}

\subsection{Role of influencers in framing knowledge}

As we continued with the analysis, we realized that a core set of "influencers" were framing the debate for others, by posting various types of contribution. To understand these influences, we mapped the social network of knowledge sources (who read whose contributions in Blackboard transaction log data) and the network of collaborators (who interacted with whom in discussions to co-construct community knowledge) [15]. 
Table 1. Analysis of problem framing (content structure) vs. knowledge building (behavior)

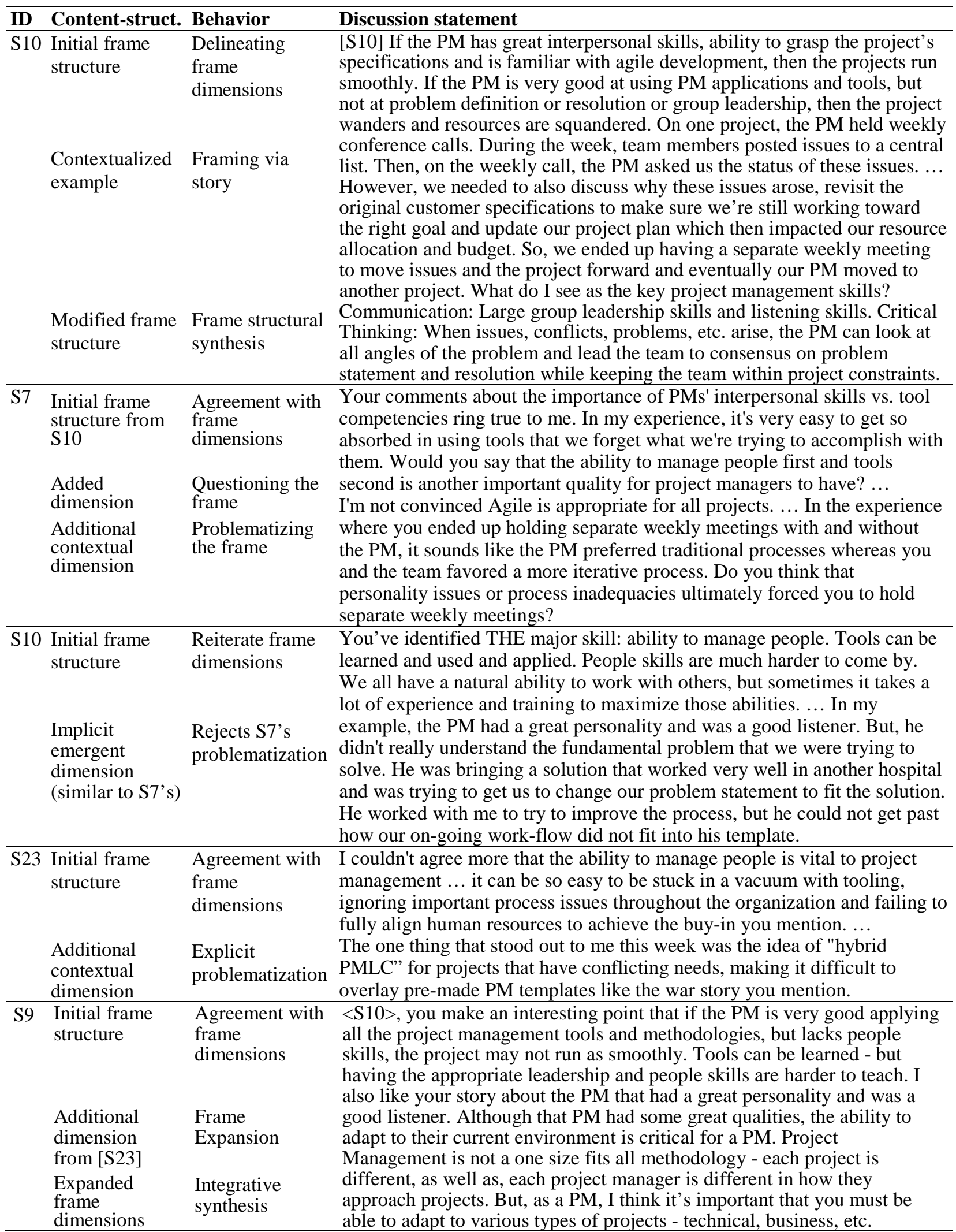


Table 2. Community knowledge-framing behaviors

\begin{tabular}{|c|c|c|}
\hline Category & Description & Example from student discussions \\
\hline $\begin{array}{l}\text { Situated framing: } \\
\text { examples, stories }\end{array}$ & $\begin{array}{l}\text { Proposed an explicit } \\
\text { structure of meaning } \\
\text { based on learner's } \\
\text { experience. Provides a } \\
\text { lens in through which to } \\
\text { understand a concept, } \\
\text { process, or problem, } \\
\text { with dimensions that } \\
\text { structure the frame. }\end{array}$ & $\begin{array}{l}\text { It is important to work with a small pilot group of users and } \\
\text { stakeholders to test and improve the first version. One of our facilities } \\
\text { went through this when developing a Clinical Virtual Desktop } \\
\text { platform. The technology was developed and tested for a small pilot } \\
\text { group first, deployed for 3-6 months with that pilot group on one } \\
\text { nursing unit and then rolled out unit by unit to make sure that the new } \\
\text { system could handle the volume. While piloting to the small group } \\
\text { we encountered many issues which we were able to resolve before } \\
\text { we delivered to entire user community. It was very successful. }\end{array}$ \\
\hline $\begin{array}{l}\text { Contextualization: } \\
\text { framing by analogy }\end{array}$ & $\begin{array}{l}\text { Suggests a structure of } \\
\text { interpretation based on } \\
\text { common situations } \\
\text { considered analogous to } \\
\text { problem-situation }\end{array}$ & $\begin{array}{l}\text { Wysocki (2014) explains that a project is not just something you do } \\
\text { around your house on a weekend and that there is an actual definition } \\
\text { of the word project and anything else that does not fall within that } \\
\text { meaning is not a project. I'm not sure I fully agree because even } \\
\text { something that needs to be completed around the home may have a } \\
\text { timeline, budget and real significant purpose, but I'll just humor him. }\end{array}$ \\
\hline $\begin{array}{l}\text { Framing by } \\
\text { exemplar: } \\
\text { conceptualization } \\
\text { using process } \\
\text { framework or } \\
\text { object-design }\end{array}$ & $\begin{array}{l}\text { Analyzes problem- } \\
\text { situation using } \\
\text { frameworks taken from } \\
\text { exemplars of process or } \\
\text { object design that work } \\
\text { in other situations. }\end{array}$ & $\begin{array}{l}\text { I propose some qualities of an effective project manager through the } \\
\text { lens of "Shuhari", a Japanese philosophy of learning and mastery } \\
\text { with roots in martial arts. ... Shuhari posits that achieving mastery } \\
\text { requires a deep knowledge of the fundamentals, then the ability to } \\
\text { innovate and challenge the fundamentals, and finally the wisdom to } \\
\text { creatively apply experience to novel situations [web-reference]. }\end{array}$ \\
\hline $\begin{array}{l}\text { Situated reflection: } \\
\text { testing fit of } \\
\text { prevailing frame } \\
\text { with context of } \\
\text { problem-situation }\end{array}$ & $\begin{array}{l}\text { Analyzes assumptions } \\
\text { about problem-situation: } \\
\text { by testing fit between } \\
\text { prevailing frame \& } \\
\text { example of prof. practice }\end{array}$ & $\begin{array}{l}\text { At my company, once a project is complete, there's a call for lessons } \\
\text { learned which would be specific things that worked well or didn't } \\
\text { work well through the project. They are then captured \& incorporated } \\
\text { in the applicable SOP for use on future projects. This is a great way } \\
\text { to get best practices that are applicable to our specific company. }\end{array}$ \\
\hline $\begin{array}{l}\text { Situated critique: } \\
\text { questioning the } \\
\text { frame }\end{array}$ & $\begin{array}{l}\text { Questions underlying } \\
\text { assumptions of the frame } \\
\text { that need to be } \\
\text { understood in more } \\
\text { detail }\end{array}$ & $\begin{array}{l}\text { I'd like to know how much money is saved with this application. If } \\
\text { the provider is large enough, the savings should justify the resources } \\
\text { needed to complete this project in a timely fashion. In my experience, } \\
\text { we don't do a very good job at identifying the "opportunity" for } \\
\text { savings before a project is initiated. }\end{array}$ \\
\hline $\begin{array}{l}\text { Frame synthesis: } \\
\text { integration of } \\
\text { structural elements } \\
\text { across posts }\end{array}$ & $\begin{array}{l}\text { Learner pulls together } \\
\text { the discussion for others } \\
\text { suggesting an explicit } \\
\text { structural framework } \\
\text { that results from } \\
\text { cumulative debate }\end{array}$ & $\begin{array}{l}\text { That seems like a good way to put it. The standards, or the core } \\
\text { elements make up a list of must-do. "Best practices" offer guidance } \\
\text { on ways of delivering the core elements. This way, a PM can look at } \\
\text { the core elements and think about whether all the core elements are } \\
\text { needed for a project, then look at a list of "best practices" and think } \\
\text { about which suits the project more. }\end{array}$ \\
\hline $\begin{array}{l}\text { Frame breakdown: } \\
\text { expose lack of fit } \\
\text { between frame and } \\
\text { context }\end{array}$ & $\begin{array}{l}\text { Discusses cause of } \\
\text { cognitive dissonance } \\
\text { introduced by trying to } \\
\text { fit prevailing frame to } \\
\text { problem-situation. }\end{array}$ & $\begin{array}{l}\text { Standards and best practices are not the same thing. ... adherence to a } \\
\text { standard can be measured objectively. If IT professionals fail to } \\
\text { comply with standards, action can be taken against them. Neither of } \\
\text { these hold true for best practices. I cannot objectively say, for } \\
\text { example, that your project is moving at } 80 \% \text { as quickly as if you were } \\
\text { using a different PMLC. }\end{array}$ \\
\hline $\begin{array}{l}\text { Problematization: } \\
\text { critique via } \\
\text { metaphors, } \\
\text { situational } \\
\text { analogies, or } \\
\text { deconstruction }\end{array}$ & $\begin{array}{l}\text { that } \\
\text { ontext } \\
\text { tion to } \\
\text { imption }\end{array}$ & $\begin{array}{l}\text { a game developer, but I've heard that "death } \\
\text { 0+ hours a week, for more than } 2 \text { months) } \\
\text { eleases are standard. Worse, it's common } \\
\text { arly the whole team after a game is completed.... } \\
\text { te low morale. But if games are released on time, } \\
\text { ec. (and sell millions of copies), should the } \\
\text { d a success? }\end{array}$ \\
\hline $\begin{array}{l}\text { Reframing: } \\
\text { propose alternate } \\
\text { frame to replace } \\
\text { one with poor fit }\end{array}$ & $\begin{array}{l}\text { Deals with frame } \\
\text { breakdown or } \\
\text { problematization by } \\
\text { proposing alternate } \\
\text { frame with better fit }\end{array}$ & $\begin{array}{l}\text { For applications that are in-scope for IT Sarbanes-Oxley (SOX) } \\
\text { compliance, any changes made to their production environment must } \\
\text { go through a change management process that adheres to SOX } \\
\text { standards. As a result, this does add somewhat of a waterfall } \\
\text { approach to development that would typically be more agile. }\end{array}$ \\
\hline $\begin{array}{l}\text { Legitimation: } \\
\text { Generalization of } \\
\text { frame for } \\
\text { community }\end{array}$ & $\begin{array}{l}\text { Produces a generalized } \\
\text { statement of a prevailing } \\
\text { frame that resulted from } \\
\text { debate, to legitimize } \\
\text { reuse in debates or } \\
\text { assignments. }\end{array}$ & $\begin{array}{l}\text { A common struggle, which we have experienced firsthand in this } \\
\text { class, is trying to estimate project duration. For unpredictable projects } \\
\text { we need to use a story telling (scenario) approach. Involving our end } \\
\text { users and our team we can map out the project features. If we time } \\
\text { box our features, we can predict where we can complete in time and } \\
\text { when the project will slip. }\end{array}$ \\
\hline
\end{tabular}




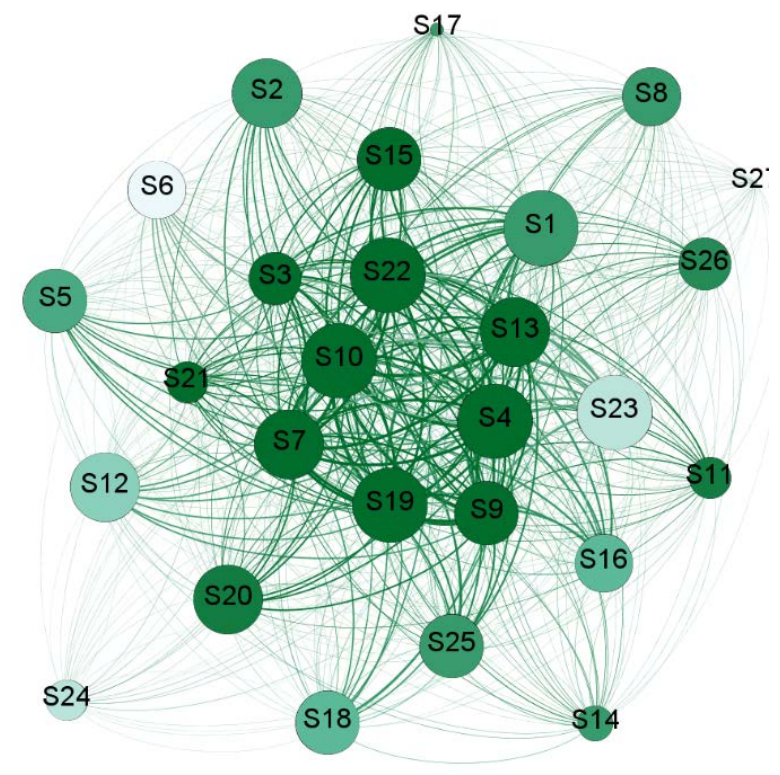

Figure 1. Knowledge Sources

Figure 1 shows how students accessed the posts of other students as a source of knowledge. We removed instructor interactions from the data so we could understand the role of peer learners in community knowledge-building. We employed a directional social network analysis, to understand who read whose posts. The in-degree centrality of this social network provides a measure of who was most influential in the network of peer learners. This measure is indicated by the size of the nodes in Figure 1. We also mapped the outdegree centrality (the extent to which a student read the ideas of others). This measure is indicated by the darkness of node shading in Figure 1. So the larger the node, the more other students read their contributions; the darker the node, the more they read course discussion posts to inform their framing of the situation. It can be seen that there is a large core of influencers shown in Figure 1: S1, S4, S7, S9, S10, S13, S15, S19, S20, S22, and S23.

With the exception of S1 and S23, all of these students read the posts of other intensively. In fact, seven students out of the class of 27 - S1, S4, S7, S10, S13, S19, S23 - accounted for $45 \%$ of all message reads, demonstrating that our influencers, mostly, had an insatiable curiosity! These students also encouraged longer threads of discussion, indicating that other students found their posts interesting and worth debating - which generally led to more complex framing debate, with the greater variety of perspectives reflected in more advanced or subtle frames.

When we examined the social network of discussion interactions, this revealed a much smaller core of influencers, as shown in Figure 2. The node size in Figure 2 indicates a student's degree centrality (connectedness to other community members). The colors indicate the degree of betweenness centrality: the darker the node, the more that student mediated between clusters of other students, the lighter the node, the more that student just interacted with a few other contacts.

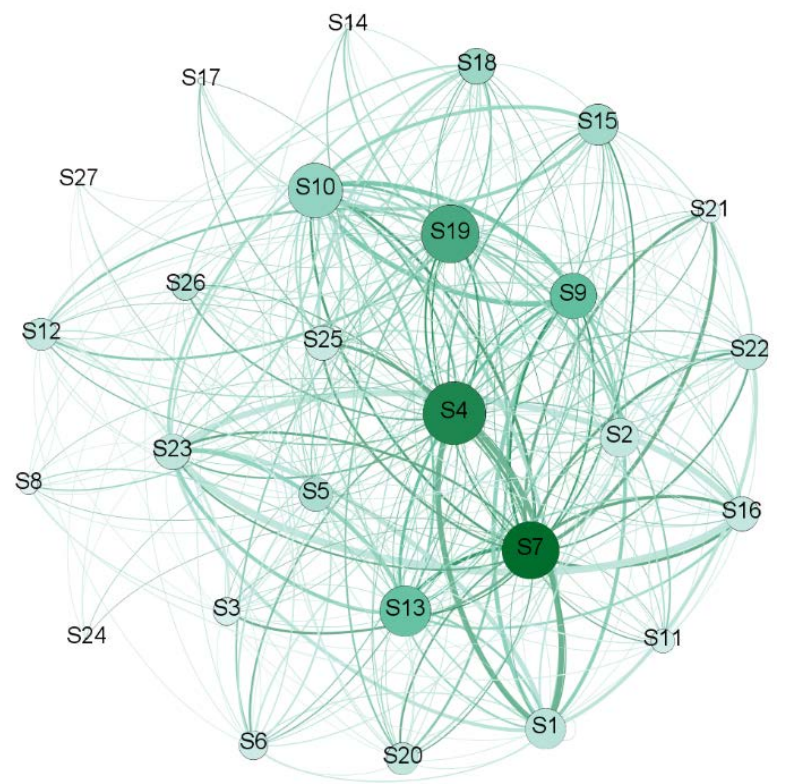

Figure 2. Framing Collaborators

Three students stand out as central to the flow of discussion in collaborative knowledge-building: S4, S7, and S19. S7 might be regarded as the epitome of a student engaged in deep and collaborative learning. S7 was active in all 4 categories of framing including synthesis and generalization (which were relatively rare behaviors). S7 also appears as highly central both in terms of posts read and messages posted as shown in the diagrams below. Only S4 shares similar (read) source and collaboration degree-centrality, but S4 fails to go beyond fairly mundane exposition, "playing it safe" with uncontentious framing suggestions in most posts. S7 had the $2^{\text {nd }}$ highest overall number of posts (S10 had 76) and typically attempts to engage others in discussion by acknowledging and critiquing important points, e.g.:

"I'm curious how that might work, because as you mention, it is difficult to compare methodologies between companies since even those that are the same in name may be different in practice." [S7 response]

So what made S4 so influential? S4 did not engage in an outstanding number of "advanced" (high-level abstraction) framing posts, post contentious content, or even post a great deal (S4 only contributed two-thirds of the number of posts made by S7). But S4's 
background was interesting. They had extensive (25 years) experience in systems development, database support, and system administration, and had worked in the Healthcare IT sector for the past seven years. So this student communicated a great deal of contextual knowledge in peer interactions - and was recognized by others for this knowledge. In comparison, S7 had worked in IT development for only four years although this was a remarkably reflective, aware individual, who obviously thought deeply about the context of their work. S19 also had extensive experience - but in data communications network management and support, rather than software development. Again, this was an exceptionally thoughtful individual, who reflected constantly on various aspects of the problem situations presented to students for discussion and would often revisit the discussion several times to make meaningful contributions.

None of the next three most influential students in discussion interactions had a background in software development. Two were employed in healthcare, as administrators responsible mainly for insurance and management of patient care. The third worked as a systems support analyst supporting a school district. All of these students had enchanting stories to tell and all three were in the lead in leading the more challenging and complex framing discussions.

\subsection{Community Knowledge-Building Processes}

Using a qualitative data analysis software package (MaxQDA), we analyzed the sequences of framebehavior, as shown in Figure 3, where purple indicates categories of context-related framing, red indicates categories of frame reflection and testing, teal indicates categories of abstract-modeling, and blue indicates legitimation and generalization.

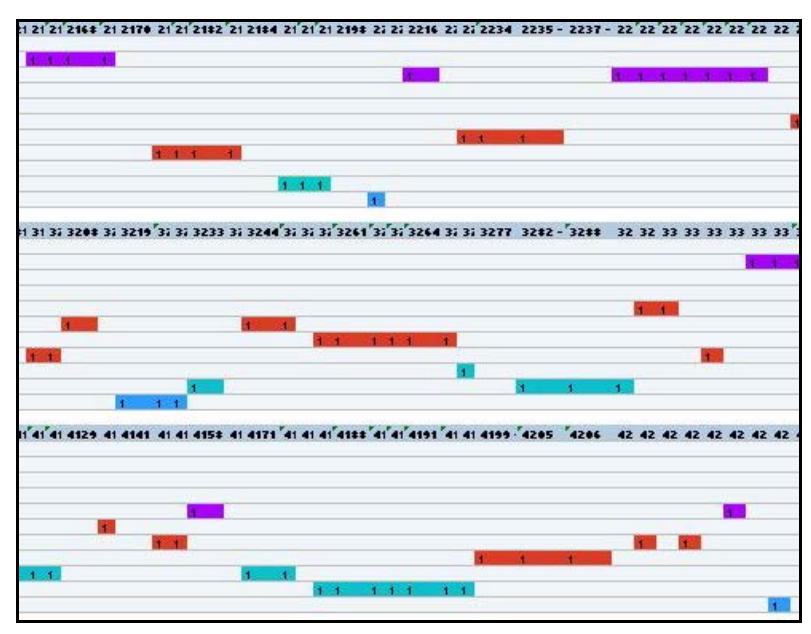

Figure 3. Sequences of Framing
As one would expect with human debate, there was no definitive (absolute) sequence of framing, but we did discern a general pattern, which was that one or more posts that employed context-related framing behaviors (Situated framing, Contextualization, or Framing by exemplar) would be followed by one or more posts that employed frame reflection and testing (Situated reflection, Situated critique, or Frame breakdown), these would be followed by one or more posts that employed abstract-modeling (Problematization, Reframing, or Frame Synthesis), followed by a Generalization/Legitimization post (these two categories were combined as they appeared to serve the same purpose).

We found that it was common for threads and posts to start by calling upon prior knowledge, either in terms of explicit acknowledgement ("One thing that I've noticed in many people's threads is ...") or implicit use of a frame that had been discussed previously ("Two key points that were brought up that I feel really nail project management are ...").

Many threads appeared to reflect upon or problematize the framing suggested in prior threads, demonstrating persistence of community knowledge across threads. It was clear that students were building upon what others had said across weeks of discussion which spanned multiple topics, as well as within weeks of discussion (focusing on a single topic). For example, one student commented at the start of a new thread: "I know what S7 will say to this idea before I even propose it, but I'm going to say it anyway!" referring to a previous week's discussion on a related topic.

Community knowledge is maintained through the discussion record, which students use strategically by focusing their effort on reading contributors whom they perceive as most knowledgeable. But persistency of community knowledge is also maintained in people's minds, as they accumulate proxy-experiential knowledge via peer discussions.

The frequency of framing behaviors, together with a meta-level categorization of these behaviors is shown in Table 3. We had expected students to be less aware of the assumptional frameworks and biases that they bring to a situation, so we were surprised at how frequently students explicitly problematized the prevailing frame. Explicit problematization posts made up one-eighth of all discussion posts (many posts made multiple contributions to framing, as shown in Table 1, but for the purposes of mapping a complex set of discussions, we categorized posts by their main contribution behavior). Contextual framing was the next most popular category of post, as students discussed how to make sense of the problem situation. With the exception of problematization, the "higher level” framing behaviors were relatively rare. 


\section{Discussion of Findings}

Table 3, below, summarizes the four meta-levels of framing that we defined from our analysis, based on grouping the framing behavior categories shown in Table 2. It became apparent from the sequence analysis shown in Figure 3 that framing behaviors followed a typical pattern of contextual or situational framing, followed by reflection upon and testing of frames for their fit with similar contexts and situations. Sometimes students would start a discussion with an implicit frame suggested by the instructor (in the problem situation discussion) or by other students in prior threads - these threads would still follow the same pattern, but with the assumptions underpinning the initial framing treated as legitimized community knowledge at the start of the thread. The high rate of problematization indicates that we may have conflated two separate behaviors, related to different mechanisms of problematization, or this may indicate that students are much more conceptually aware than instructors give them credit for!

Figure 4 illustrates the resulting model of community knowledge framing observed in this study. It demonstrates how students move between the first form of knowing, which builds individual, distributed knowledge (knowledge which is stretched across - or between - participants), and the second form of knowing, which builds and legitimizes group knowledge by proposing and contextualizing an emergent collective frame (knowledge which is shared by participants),. From the findings presented above, we conceptualize community knowledge construction as moving from an individual level of contextualization, through reflective fitting between the contextual factors suggested by others, in the contextual frame of students' own experience of similar situations or the frame provided by narrative accounts of the experiences of others. This results in some form of problematization, as the assumptions and structures of interpretation are surfaced in a social context. Other discussants enter the debate, to qualify, modify, and reframe the problem-situation. Finally, the community agrees on a consensus perspective and this is objectified, generalized and legitimized through discussion, agreement, and summaries, to act as an object of community "truth" that can be built upon in future debates.

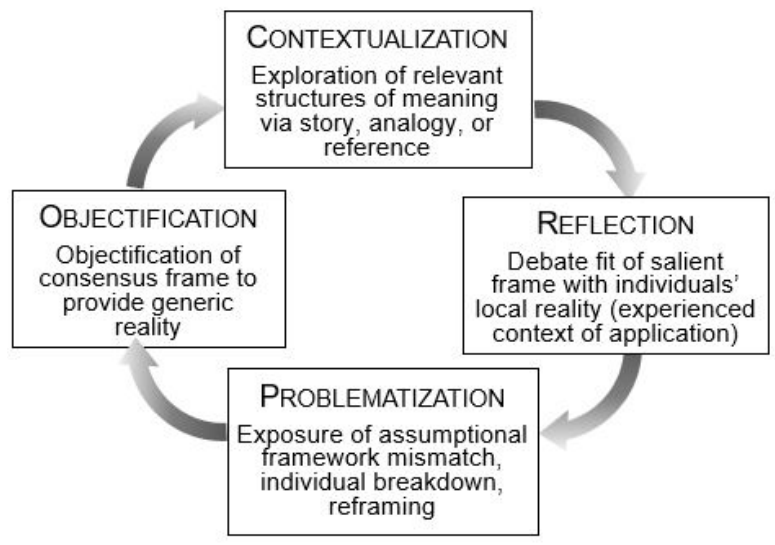

Figure 4. Framing Community Knowledge

The model in Figure 4 illustrates our initial conceptualization of how the various modes of framing that we observed combine to build a genericallysubjective form of community-accepted knowledge [16] through sequences of interaction. This is not an individual learning cycle, but reflects interaction effects between individual, community, and societal realities, in the social construction of reality [1]. In this context, interaction effects occur between individual framing (contextualization and reflection), interactive behavior (problematization), and community consensus-building (objectification/generalization).

Table 3. Four Levels of Framing Complexity in Collaborative Debate

\begin{tabular}{l|l|l}
\hline Meta-behavior & Forms of framing (freq.) & Explanation \\
\hline Contextualization & $\begin{array}{l}\text { Situated framing (152) } \\
\text { Contextualization (101) } \\
\text { Framing by exemplar (139) }\end{array}$ & $\begin{array}{l}\text { Individual learners propose, critique, or adapt a frame by } \\
\text { reference to a specific context of application. Typically presented } \\
\text { via a story, analogy, or needs of a specific type of situation. }\end{array}$ \\
\hline Reflection & $\begin{array}{l}\text { Situated reflection (144) } \\
\text { Frame challenging (76) } \\
\text { Frame breakdown (40) }\end{array}$ & $\begin{array}{l}\text { A proxy form of reflection-in-action, where learner uses } \\
\text { examples from experience to test application of salient frame. }\end{array}$ \\
\hline Problematization & $\begin{array}{l}\text { Problematization (104) } \\
\text { Reframing (55) } \\
\text { Frame synthesis (38) }\end{array}$ & $\begin{array}{l}\text { Explicit or implicit exposure and replacement of assumptions } \\
\text { using a metaphor, description of context in which frame does not } \\
\text { fit, or exploration of consequences. }\end{array}$ \\
\hline Objectification & $\begin{array}{l}\text { Generalization and } \\
\text { Legitimation (35) }\end{array}$ & $\begin{array}{l}\text { Abstraction and application to generic circumstances, to } \\
\text { legitimize frame and create a community knowledge object that } \\
\text { can be accepted by all learners. }\end{array}$ \\
\hline
\end{tabular}




\section{Conclusions}

This paper presents a framework for knowledgebuilding behaviors and a model of community knowledge construction (as distinct from dialogic argumentation which analyzes individual debate roles). As well as explaining the community knowledgebuilding that underpins peer learning, the behaviors noted here may well be transferable to other online environments where a consideration of context is important to sensemaking for various problemsituations. We close with a model that demonstrates how community knowledge is co-constructed through sequences of contextualized frame-proposal, reflective comparison with own experience, frameproblematization and debate, and generic-legitimation of a consensus frame.

The model shown in Figure 4 only works because of the key set of peer influencers that students can call upon, to validate their own frames and to explore how others make sense of the problem-situation under discussion. The persistence of asynchronous, online discussions means that peers can exert this influence over the duration of the course - and beyond, as students take this learning with them.

We note that an enthusiastic core of curious and thoughtful influencers, who are reflective, thoughtful, and also sociable in their interactions, is required for community knowledge building to be successful. The implications for practice are that we need to manage the social affordances of collaboration as well as technical affordances: the management of expectations, providing an incentive scheme that rewards collaboration and complication of debate, and providing early formative feedback are all essential to effective community knowledge-building.

\section{References}

[1] Berger, Peter L., and Thomas Luckmann. The social construction of reality. Penguin UK, 1991.

[2] Bijker, W.E., "The Social Construction of Bakelite", in W.E. Bijker, T.P. Hughes, and T.J. Pinch, (eds.): The Social Construction of Technological Systems, MIT Press, Cambridge MA, 1987, pp. 159-187.

[3] Foucault, M., "Discourse and truth: The problematization of parrhesia", in J. Pearson (ed.), Fall 1983 Lectures at Univ. of California Berkeley, 1985. http://foucault.info/parrhesia/

[4] Garrison, R. and Cleveland-Innes, M., "Facilitating Cognitive Presence in Online Learning: Interaction Is
Not Enough", American J. Of Dist. Ed., 19(3), 2005, pp. 133-148.

[5] Glaser, B.G. and Strauss, A.L., The Discovery of Grounded Theory, Aldine Pub., New York NY, 1967.

[6] Goffman, E., Frame Analysis, Harper and Row, New York, NY, 1974.

[7] van Gorp, B., "Strategies to take subjectivity out of framing analysis", in P. d'Angelo and J. Kuypers, (eds.): Doing news framing analysis: Empirical and theoretical perspectives, Routledge, Abingdon, 2010.

[8] Lave, J. and Wenger, E., Situated Learning: Legitimate Peripheral Participation, Cam. Univ. Press, Cambridge 1991.

[9] Marton, F., \& Säljö, R. (1976). On qualitative differences in learning: I - Outcome and process. British journal of educational psychology, 46(1), pp. 411.

[10] Pearson, E., "All the World Wide Web's a stage: The performance of identity in online social networks", First Monday, 14(3), 2009.

[11] Pellizzoni, L., "Metaphors and Problematizations. Notes for a Research Programme on New Materialism", Tecnoscienza: Italian Journal of Science \& Technology Studies, 5(2), 2015, pp. 73-92.

[12] Scardamalia, M. and Bereiter, C., "Knowledge building: Theory, pedagogy, and technology", in K. Sawyer, (ed.): Cambridge Handbook of the Learning Sciences, Cambridge University Press, New York, 2006, pp. 97-118.

[13] Schön, D.A., Educating the Reflective Practitioner, Jossey-Bass, San Francisco, CA., 1987.

[14] Tannen, D., "Frames and Schemas in Interaction", Quaderni di Semantica, 6(2), 1985, pp. 326-335.

[15] Waters, J. and Gasson, S., "Supporting Reflective, Peer and Vicarious Learning in Online, Professional Graduate Courses", Hawaii Intl. Conference on System Sciences (HICSS-48), 4-8 Jan. 2015.

[16] Weick, K.E., Sensemaking In Organizations, Sage, Thousand Oaks CA, 1995.

[17] Winograd, T. and Flores, F., Understanding Computers And Cognition, Ablex Corp., Norwood New Jersey, 1986. 